\title{
Using A 360-Degree Appraisal Approach To Re-Design Advising Programs
}

Glenn Maples, Northwestern State University, USA

Ms. Bette Harris, University of Louisiana-Lafayette, USA

Ms. Anna M. Greco, University of Louisiana at Lafayette, USA

\begin{abstract}
Over the past 30 years, researchers have repeatedly demonstrated the need to improve academic advising. Nonetheless, at many Universities academic advising remains a neglected endeavorpoorly measured, managed and rewarded. This paper considers the implementation of an academic advising program which parallels the 360-Degree feedback approach drawn from the Human Resources Management discipline. The details of the program are outlined and preliminary results of the program, which literally transformed academic advising at our institution, are discussed.
\end{abstract}

\section{THE CURRENT STATE OF ACADEMIC ADVISING}

$\mathrm{n}$ a broad sense, many of the primary research issues regarding academic advising at the University level - have not changed much over the past 30 years. Then as now, advising researchers considered the and the use of technology to improve advising (e.g., Lacher 1978; Teague and Grites 1980; and Sewart 1980 respectively).

However, recent trends accentuate the importance of investigating these issues. Increasing student employment loads, transfer rates, and emphases on universal student access tend to compound the complexities of advising. Meanwhile, increased research expectations, even in institutions whose mission has traditionally been teaching-focused, have resulted in a substantial reduction in time devoted to advising compared to the average time of faculty members measured 20 years ago. (Milem, Berger and Day 2000)

The changing nature of high education has made academic advising more difficult due to changing missions, students, faculty, and delivery. However, unease over the adequacy of academic advising is nothing new. For instance, Russel and Thomas (1979) expressed serious reservations over the efficacy of faculty advising for first-year students.

What is new is the confluence of trends making academic advising more challenging today that at any other modern time. University students have to focus more on outside employment-fifty percent of undergrads have federal loans compared to about 30 percent from 10 years ago (Livingston 2006). Students are taking longer to earn that "4-year" degree - nationally more than 40 percent of undergrads who do earn a degree are taking 5 or 6 years to do so( Knapp, Kelly-Reid and Whitmore 2006). Students are less academically ready for college - between 30 and 60 percent of university students need academic remediation on entering the university (Conley 2006). These national trends among other complexities due to specific missions of individual institutions are exponentially increasing the complexity of advising.

Meanwhile, determining the overall objective of academic advising has become more complex as well. Academic advising provides an important role in efforts to increase student access, retention and graduation rates, as well as to decrease both the time students take to earn a degree and the overall cost of providing a college education. Moreover, in a time of changing institutional missions it is difficult for many academic advisors to know the organizational mission much less align to their advising behaviors with that mission. 


\section{DECIDING ON A 360 - DEGREE APPROACH}

Our institution is a large, publicly funded university located in the southern United States. We believe that the state of advising at our school two years ago is typical of that at many other universities today.

Despite its stated importance, the quality of faculty advising was not measured or reported at the University or College level. Much of this omission can be attributed to the higher weight usually given other faculty activities. In many faculty and administration minds, student advising received little weight compared to that given research, teaching, grant writing and university service. And, in this environment, it is unlikely that advising would play a significant role in performance appraisals.

The primary recognition given for advising was an annual, university-level, advising award. The award itself was given at an honors convocation sparsely attended by faculty members. Our experience with this award underscored the wide variety of approaches to advising on the part of our faculty.

We realized that we had the following challenges:

1) The need to implement an organizational-wide change;

2) A focus on advisor development rather than appraisal;

3) the varying needs of students and styles of faculty required a holistic approach as there was no single "correct" way to advise; and,

4) The need to get the "buy-in" of our faculty.

\section{A FORMAL MANAGEMENT APPROACH}

The 360-Degree Feedback approach provides a consistent management philosophy meeting the criterion outlined previously. The 360-degree feedback appraisal process describes a human resource methodology that is frequently used for both employee appraisal and employee development. Used in employee performance appraisals, the 360-degree feedback methodology is differentiated from traditional, top-down appraisal methods in which the supervisor responsible for the appraisal provides the majority of the data. Instead it seeks to use information gleaned from other sources to provide a fuller picture of employees' performances. Similarly, when this technique used in employee development it augments employees' perceptions of training needs with those of the people with whom they interact.

The 360-degree feedback approach has two fundamental tenets: 1) the most effective approach to changing behavior is through feedback; and, 2) the various stake holders interacting with an individual provide the richest source of information for this feedback. (See Figure 1).

Research has demonstrated measurable benefits to the technique; for instance, Brett (2006) measured a positive correlation between the use or 360 degree feedback and the increases in job satisfaction. Another advantage to the approach is that the use of many inputs tends to reduce rater bias (Taversky and Kahnneman 1974). Eischenger (2004) shows that rater accuracy tends to decrease over time, with those who have known the employee for more than five years to be least accurate in providing feedback.

The 360-Degree approach is particularly well-suited to help bring about change to a long standing problem. As Jack Welch puts it - "Its [360-Degree Feedback] main value is to "out" the unspoken."

Criticisms of 360-Degree feedback generally are focused on its use in appraisal rather than development settings. These drawbacks include the possibility of too much negative feedback as well as employees "gaming" the system. That is, since employees rate each other they may enter into agreements that result in mutual backscratching. 


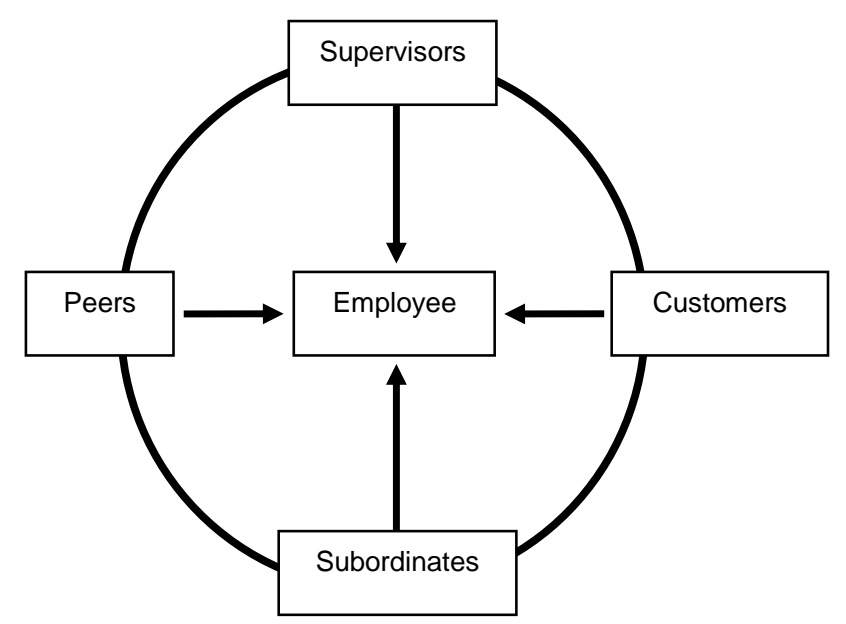

Figure 1 - Standard Performance Feedback for 360-degree Appraisal

\section{IMPLEMENTING A 360-DEGREE APPROACH TO ADVISING APPRAISAL:}

More than any other factor, executive sponsorship determines the success or failure of changes introduced into organizations (Hickens 1998). The reordering of priorities to emphasize advising is a monumental cultural change in an academic institution. Several years ago advising was identified as an important opportunity for improvement of our institution and we were fortunate enough to have our university president participate at the Board of Reagents level to lead our change.

Our president also provided more tangible leadership, committing $\$ 50,000$ per year for advising awards. Faculty members with more than 3 years of experiences were eligible for 1 of 45 one-thousand dollar awards. Newer faculty members were eligible for 20 five-hundred dollar awards. Additionally he agreed to sponsor and participate in an annual awards ceremony for the winning advisors. In addition to inviting the winning advisors and their family members, deans and department heads were also encouraged to attend. Now armed with the full attention of administration and faculty it became possible for us to develop our full advising plan using the new advising awards as our catalyst for change.

As shown in Figure 2, our advising program uses a 360-degree appraisal system. The four main inputs into this process are provided by Department Heads and Deans (Supervisors), Students (subordinates and customers), the Advising Committee (peers), and academic administration.

Students provide an important source of information, having an opportunity to rate their advisor when they register online. The rate their advisors on a 10-point Likert scale on 9 items as shown in Table 1.

Table 1-Student Rating Items

Knowledge of major requirements:

Knowledge of course offerings and prerequisites:

Punctuality for scheduled appointments:

Awareness of my academic progress:

Amount of time spent with me is sufficient:

Listening skills and ease of conversation:

Suggestion of alternatives with academic difficulties:

Suggestion of resources for assistance:

Help in preparing you for life after graduation: 
The Advising Office shepherded the new advising plan. To foster increases in advising quality, the advising office published a list of screening criteria to be used in determining the winners of the awards. These criteria included attending a minimum number of advising workshops, advising a minimum number of students, and giving additional consideration to advisors who participated in special advising sessions.

Deans and department heads provided rankings of all advising faculty members.

The advising committee provided the final determination of award winners based on the rankings provided by deans and department heads, the ratings given by students and statements from applicants detailing their academic advising philosophies, methods and innovations. Three faculty members, three students, two academic deans, two professional advisors and a representative of the Advising Office make up the advising committee.

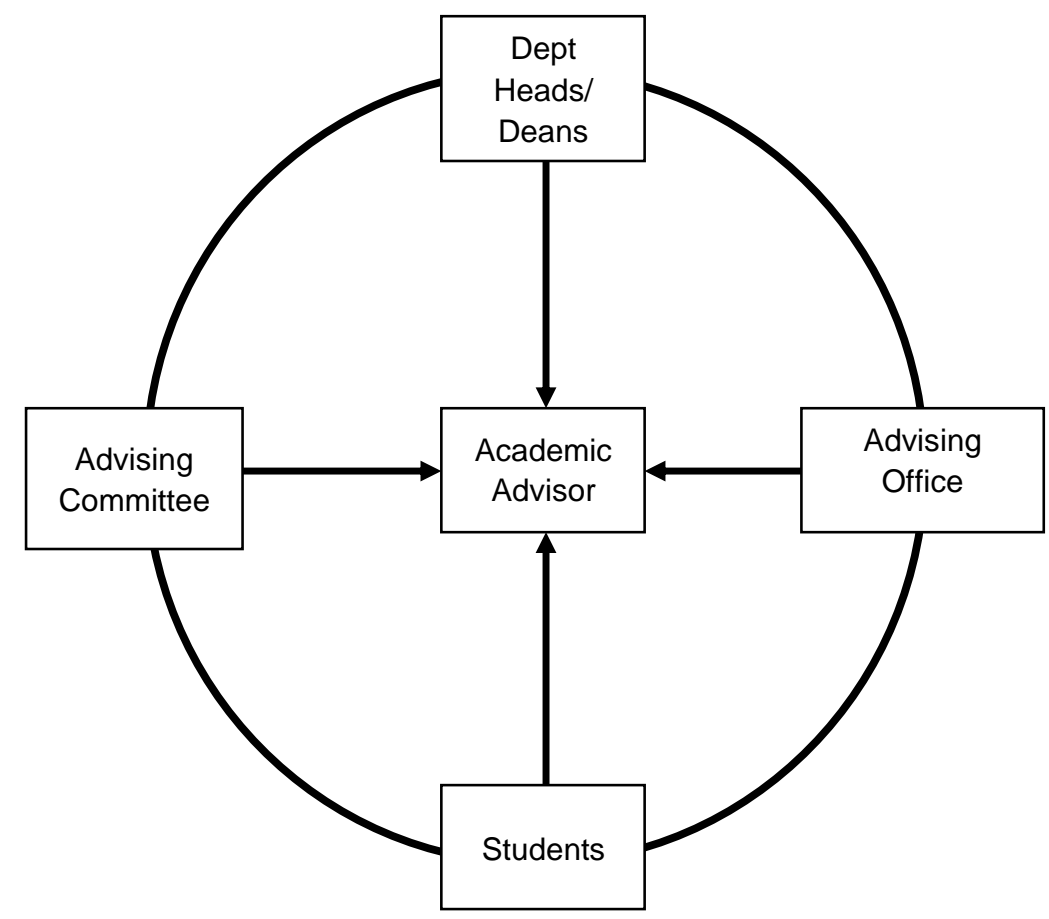

Figure 2 - Advising 360-degree Feedback

\section{EMPIRICAL RESULTS}

The empirical results discussed in this paper focus on the student perceptions of advising from responses to an advising survey offered during registration.

\section{Confirmatory Factor Analysis:}

To verify that the nine items in the advising survey loaded on a single construct, a confirmatory factor analysis was conducted, resulting in a single factor accounting for $74.7 \%$ of the variance (Table 2). These results are consistent with a single underlying construct being largely responsible for student perceptions of advising. 
Table 2 - Factor Analysis of Instrument Items

\begin{tabular}{|c|c|c|c|c|c|c|}
\hline \multirow[b]{2}{*}{ Component } & \multicolumn{3}{|c|}{ Initial Eigenvalues } & \multicolumn{3}{|c|}{ Extraction Sums of Squared Loadings } \\
\hline & Total & $\%$ of Variance & Cumulative \% & Total & $\%$ of Variance & Cumulative \% \\
\hline 1 & 6.723 & 74.704 & 74.704 & 6.723 & 74.704 & 74.704 \\
\hline 2 & .578 & 6.420 & 81.124 & & & \\
\hline 3 & .461 & 5.120 & 86.244 & & & \\
\hline 4 & .347 & 3.856 & 90.100 & & & \\
\hline 5 & .261 & 2.897 & 92.997 & & & \\
\hline 6 & .193 & 2.140 & 95.137 & & & \\
\hline 7 & .162 & 1.796 & 96.933 & & & \\
\hline 8 & .155 & 1.726 & 98.658 & & & \\
\hline 9 & .121 & 1.342 & 100.000 & & & \\
\hline
\end{tabular}

Extraction Method: Principal Component Analysis.

\section{DIFFERENCES BY CLASS}

A principal question addressed in the research is whether students at different levels perceive the quality of advising differently. Specifically, it was hypothesized that differences, if they existed, were likely to occur either as student progressed through their degrees. Specifically, it was thought that seniors and graduate students were likely to rate their advisors more favorable as they were likely to have formed stronger relationships with faculty and advisor than other undergraduate students.

To consider this question, students were grouped by class and then their means on overall perceptions of the advising process were compared. A surrogate variable for overall perceptions was constructed by averaging respondents' responses on the 9 items previously shown to load on a single factor. The simple means are reported in Table 3.

Table 3 - Overall Perceptions of Advising by Class

\begin{tabular}{|l|c|c|c|}
\hline \multicolumn{1}{|c|}{ Class Standing } & Mean & N & Std. Deviation \\
\hline Freshman & 8.8661 & 2776 & 1.39563 \\
\hline Sophomore & 8.8469 & 2211 & 1.50357 \\
\hline Junior & 8.9044 & 2061 & 1.48525 \\
\hline Senior & 9.0244 & 2009 & 1.52921 \\
\hline Graduate & 9.4475 & 539 & 1.01019 \\
\hline Total & 8.9357 & 9596 & 1.45741 \\
\hline
\end{tabular}

The reported means suggest significant differences may exist between classes. Thus, a standard one-way Analysis of Variance was conducted with class standing used for its factors followed by Tukeys HSD, a post hoc test allowing computation of significance between groups. The results of this test are summarized in table 4 .

Table 4 - Significance of Tukey Mean Comparisons

\begin{tabular}{|l|c|c|c|c|c|}
\hline \multicolumn{1}{|c|}{ Class } & Freshman & Sophomore & Junior & Senior & Graduate \\
\hline Freshman & - & .990 & .894 & .002 & .000 \\
\hline Sophomore & & - & .696 & .001 & .000 \\
\hline Junior & & & - & .063 & .000 \\
\hline Senior & & & & - & .000 \\
\hline Graduate & & & & & - \\
\hline
\end{tabular}

These results show the significance of differences in the mean satisfaction reported in Table 2. Thus, graduate student means are significantly higher than those of all other groups and seniors have significantly higher means than sophomores and juniors. These results agree with the hypothesis that students typically will rate advising higher the further they have progressed in college. 
Analysis was also performed on ratings from transfer students compared to those of students who originally enrolled at the University. Table 5 shows the outcome -- Although transfer students rated their advisors lower, the difference was insignificant $(\mathrm{p}=.340)$. However, Levene's test showed a significant difference between the variances of the two groups $(\mathrm{p}=.011)$.

Table 5 - Overall Advising Perceptions by Transfer Status

\begin{tabular}{|l|c|c|c|}
\hline \multicolumn{1}{|c|}{ Transfer Status } & Mean & N & Std. Deviation \\
\hline Transfer & 8.9005 & 1163 & 1.55772 \\
\hline Non-Transfer & 8.9440 & 8364 & 1.44112 \\
\hline Total & 8.9387 & 9527 & 1.45584 \\
\hline
\end{tabular}

\section{CHANGES IN PERCEPTIONS OF ADVISING}

Before the changes to the student instrument, student responses were collected using a 4 point Likert scale (Strongly Agree, Agree, Disagree, and Strongly Disagree). Our revised instrument uses a 10 point scale. Any comparisons of means between these instruments would be problematic — even scaling would not solve the problem of taking essentially ordinal data and converting it to interval. Thus, rather than comparing means, we decided to use a Pearson's Chi Square test by recoding the overall perceptions on the surveys into two categories - one above each surveys' midpoint and one below each survey's midpoint. The result was to combine Agree and Strongly Agree as well as Disagree and Strongly Disagree on the data obtained from a prior year and compare that to the groups determined by $1-5$ and 6-10 on the new survey. While not as statistically strong as a means comparison, this chi square test is much more statistically valid.

The results of this Chi Square test are reported in Table 6. This table demonstrates a huge increase in student satisfaction - for instance about $8 \%$ of the students selected either disagree or strongly disagree for their level of satisfaction; however, less that $3 \%$ of the students taking the new survey categorize their overall satisfaction as negative. The resulting Chi Square statistic was highly significant $(\mathrm{p}=.000)$.

Table 6 - Comparison of Student Satisfaction (Old and New Surveys)

\begin{tabular}{|l|c|c|c|}
\hline Observed/Expected Values & New Instrument & Old Instrument & Sum \\
\hline Not Satisfied & $271 / 451$ & $422 / 242$ & 693 \\
\hline Satisfied & $9140 / 8959$ & $4614 / 4794$ & 13754 \\
\hline Sum & 9411 & 5036 & 14447 \\
\hline
\end{tabular}

\section{CONCLUSION, LESSONS LEARNED AND FUTURE RESEARCH}

One of the main advantages of a 360-degree feedback is the mutual investment in the outcome of the appraisal by all stakeholders. The contributions of so many stakeholders to a common enterprise create a level of energy that almost takes on a life of its own.

As shown in Table 6, there has been a tremendous increase in the student's perception of advising since implementing the new program. There has also been a corresponding increase in faculty efforts. Faculty attendance in advising workshops has markedly increased, from 210 in 2004 to 354 in 2005 and 641 in 2006 . By all measures, this program has been incredibly successful.

A major point of further research is finding out if there is any way to reach a small group of faculty that score far below the rest of their peers on the various components to this appraisal process. Similarly, there is a relatively small group of students who seem very dissatisfied with their advisors, is there a way to characterize these students that would make it possible to increase their satisfaction with the advising process? Another important trend is students concern with employability, this may cause us to rethink the end point of the advising process as well as the services provided seniors and graduate students as part of advising. 
Of course, better advising should be thought of as a means enabling the ultimate end of improving student performance in school-leading to better grades, increased satisfaction, and increased retention. The current study stops well short of assessing these macro-level organizational gains. But, it does demonstrate that a well constructed advising program that follows the mantra of 360-degree feedback by soliciting the participation of all relevant stakeholders and using that feedback to construct a rich appraisal system can lead to substantial increases in advising quality.

\section{REFERENCES}

1) Brett, J. (2006) "360 Degree Feedback to Leaders." Group and Organization Management 31 578-600.

2) Conley, D. (2006) "What We Must Do to Create a System that Prepares Students for College Success" Policy Perspectives." WestEd

3) Eichinger, R. (2004) "Patterns of Rater Accuracy in 360-degree Feedback" Perspectives 2723-25.

4) Hickins, M., (1998) "Running the change gauntlet" Management Review. New York 87(11); pg. 7,-8. pgs

5) Knapp, L.; Kelly-Reid, J.; Whitmore, R. (2006 ) "Enrollment in Postsecondary Institutions, Fall 2004; Graduation Rates, 1998 \& 2001 Cohorts; and Financial Statistics, Fiscal Year 2004” NCES 2006-155 National Center for Education Statistics.

6) Lacher, M. (1978) "Advising Undergraduate Women - Psychologists Advice To Academic Advisers" Journal Of College Student Development 19 (6): 488-493

7) Livingston, A. (2006) "The Condition of Education 2006 in Brief. NCES 2006-07" National Center for Education Statistics.

8) Milem, J., Berger, J. and Dey, E. (2000) "Faculty Time Allocation: A Study of Change over Twenty Years" Journal of Higher Education, v71 n4 p454-75.

9) Russel, J. and Sullivan, T. (1979) "Student Acquisition of Career Decision-Making Skills as a Result of Faculty Advisor Intervention” Journal of College Student Personnel, v20 n4 p291-96.

10) Sewart, D. (1980) "Creating an Information Base for an Individualized Support System in Distance Education" Distance Education, v1 n2 p171-87 Sep 1980.

11) Teague G.V., Grites T.J. (1980) "Faculty Contracts And Academic Advising “ Journal Of College Student Development 21 (1): 40-44.

12) Tversky, A., and Kahneman, D. (1974). "Judgment under uncertainty: heuristics and biases". Science, 185, pp.1124-1131.

13) Welch, J and Welch, S. “The Importance of Being There” Business Week, 00077135, 4/16/2007, Issue 4030 
NOTES 